\title{
A case of thrombotic thrombocytopenic purpura induced by acute pancreatitis
}

This article was published in the following Dove Press journal:

International Journal of General Medicine

27 March 2012

Number of times this article has been viewed

\author{
Miyoko Arimoto' \\ Yutaka Komiyama² \\ Fumiko Okamae' \\ Akemi Ichibe' \\ Setsuko Teranishi ${ }^{\prime}$ \\ Hirohiko Tokunaga' \\ Keiko Nakaya ${ }^{3}$ \\ Michie Fujiwara ${ }^{3}$ \\ Manabu Yamaoka ${ }^{4}$ \\ Shuji Onishi ${ }^{4}$ \\ Rie Miyamoto ${ }^{5}$ \\ Naoto Nakamichi ${ }^{5}$ \\ Shosaku Nomura ${ }^{5}$ \\ 'Blood Transfusion Unit, Kansai \\ Medical University Takii Hospital, \\ ${ }^{2}$ Department of Clinical Sciences \\ and Laboratory Medicine, Kansai \\ Medical University, ${ }^{3} \mathrm{Clinical}$ Medical \\ Technology Unit, Kansai Medical \\ University Takii Hospital, ${ }^{4}$ Blood \\ Transfusion Unit, Kansai Medical \\ University Hirakata Hospital, ${ }^{5}$ First \\ Department of Internal Medicine, \\ Kansai Medical University, Moriguchi, \\ Japan
}

Correspondence: Shosaku Nomura 10-15, Fumizono-Cho, Moriguchi-City, Osaka 570-8507, Japan

$\mathrm{Tel}+8 \mathrm{I} 669939453$

Fax +8I 669921293

Email nomurash@hirakata.kmu.ac.jp

\begin{abstract}
Thrombotic thrombocytopenic purpura (TTP) is a multisystemic microvascular disorder that may be caused by an imbalance between unusually large von Willebrand factor multimers and the cleaving protease ADAMTS13. In acquired TTP, especially in secondary TTP with various underlying diseases, the diagnosis is difficult because there are many cases that do not exhibit severe deficiency of ADAMTS13 or raised levels of ADAMST13 inhibitors. It is well known that collagen disease, malignancy, and hematopoietic stem cell transplantation can be underlying conditions that induce TTP. However, TTP induced by acute pancreatitis, as experienced by our patient, has rarely been reported. Our patient completely recovered with treatments using steroids and plasma exchange (PE) only. In cases where patients develop acute pancreatitis with no apparent causes for hemolytic anemia and thrombocytopenia, the possibility of TTP should be considered. Treatments for TTP including PE should be evaluated as soon as a diagnosis is made.
\end{abstract}

Keywords: thrombotic thrombocytopenic purpura, ADAMTS13, acute pancreatitis, plasma exchange

\section{Introduction}

Thrombotic thrombocytopenic purpura (TTP) is a life-threatening disorder. ${ }^{1,2}$ It is recognized that TTP may be induced by an imbalance between unusually large von Willebrand factor multimers (ULVWFM) and a disintegrin-like metalloprotease with thrombospondin type 1 motif 13 (ADAMTS13), which often leads to the formation of microthromboses. ${ }^{1-3}$ ADAMTS13 cleaves ULVWFM with platelet aggregation. Severe deficiency of ADAMTS13 activity or excessive ULVWFM can cause microthrombosis and result in TTP.

Congenital TTP (Upshaw-Schulman syndrome) is characterized by the absence or severe deficiency of ADAMTS13 activity by mutations in the ADAMTS13 gene. Acquired idiopathic TTP without underlying diseases generally has severe deficiency of ADAMTS13 activity caused by anti-ADAMTS13 autoantibodies. However, acquired secondary TTP due to various underlying diseases often does not show a severe deficiency of ADAMTS13 activity or the presence of ADAMTS13 inhibitors. TTP without severe ADAMTS13 deficiency is described as thrombotic microangiopathy (TMA). ${ }^{3}$ It is well known that these secondary TTPs are associated with collagen disease, malignancy, and hematopoietic stem cell transplantation. ${ }^{1,3}$ Furthermore, on rare occasions, acute pancreatitis can also be a trigger for TTP.,

Since the discovery that plasma exchange (PE) is an effective treatment for TTP, the survival of patients with TTP has dramatically increased. ${ }^{6}$ However, in secondary TTP 
with normal or moderately reduced ADAMTS13 activity and no evidence of ADAMTS13 inhibitor, PE is not effective in many cases. ${ }^{7}$ We report a case of secondary TTP induced by acute pancreatitis, in which PE was effective.

\section{Case report}

A woman in her forties with acute epigastric pain and vomiting had been admitted. Computed tomography scan had revealed an enlargement of the pancreas. Common bile duct stones were not detected. She had been diagnosed with acute pancreatitis caused by alcohol and had started having treatment for this condition. On day 1, amylase was high at $1614 \mathrm{U} / \mathrm{L}$. The number of white blood cells was also high at $155 \times 10^{2} / \mu \mathrm{L}$. Hemoglobin $(\mathrm{Hb})$ was slightly low at $10.8 \mathrm{~g} / \mathrm{dL}$. Platelet counts were high at $45.7 \times 10^{4} / \mu \mathrm{L}$ (Table 1). Therefore, initially, clinical symptoms and laboratory data only showed signs of acute pancreatitis. Amylase was decreased on day 3 and the symptoms of pancreatitis were resolving. However, on day 4, she had an unexplained sharp fall in $\mathrm{Hb}$ and platelet counts, which were $4.2 \mathrm{~g} / \mathrm{dL}$ and $2.7 \times 10^{4} / \mu \mathrm{L}$, respectively. She was transfused with platelet cells (PC) 10 units (U) and red cell concentrate 6 U. Despite the transfusion, she showed no improvement. She was transferred to our hospital on day 5 to investigate anemia.

Laboratory data on admission to our hospital (day 5) are shown in Table 2. They showed hemolytic anemia and thrombocytopenia; $\mathrm{Hb}$ and platelet counts were low at $7.4 \mathrm{~g} / \mathrm{dL}$ and $2.4 \times 10^{4} / \mu \mathrm{L}$, respectively. Lactate dehydrogenase was high at $2121 \mathrm{U} / \mathrm{L}$. Total bilirubin was also high at $3.0 \mathrm{mg} / \mathrm{dL}$. Haptoglobin was extremely low at less than $10 \mathrm{mg} / \mathrm{dL}$. The results also showed renal failure; creatinine was $2.51 \mathrm{mg} / \mathrm{dL}$ and the estimated glomerular filtration rate

Table I Laboratory data on pre-admission

\begin{tabular}{lllll}
\hline Days from diagnosis & day I & day 2 & day 3 & day 4 \\
\hline $\mathrm{WBC} \times 10^{2} / \mu \mathrm{L}$ & 155 & $\mathrm{NT}$ & 232 & $\mathrm{I} 4 \mathrm{I}$ \\
$\mathrm{RBC} \times 10^{4} / \mu \mathrm{L}$ & 478 & $\mathrm{NT}$ & 360 & 203 \\
$\mathrm{Hb} \mathrm{g/dL}$ & 10.8 & $\mathrm{NT}$ & 7.5 & 4.2 \\
$\mathrm{PLT} \times 10^{4} / \mu \mathrm{L}$ & 45.7 & $\mathrm{NT}$ & 10.2 & 2.7 \\
$\mathrm{AMY} \mathrm{U/L}$ & 1614 & $\mathrm{NT}$ & 473.5 & $\mathrm{NT}$ \\
$\mathrm{T}-\mathrm{Bil} \mathrm{mg/dL}$ & 0.34 & $\mathrm{NT}$ & 2.88 & $\mathrm{NT}$ \\
$\mathrm{D}-\mathrm{Bil} \mathrm{mg/dL}$ & 0.1 & $\mathrm{I} T$ & $\mathrm{NT}$ & $\mathrm{NT}$ \\
$\mathrm{LDH} \mathrm{U} / \mathrm{L}$ & 317 & 2209 & $\mathrm{NT}$ & $\mathrm{NT}$ \\
$\mathrm{CRTN} \mathrm{mg/dL}$ & 0.37 & $\mathrm{NT}$ & 2.72 & $\mathrm{NT}$ \\
$\mathrm{CRP} \mathrm{mg} / \mathrm{dL}$ & 0.28 & $\mathrm{NT}$ & $\mathrm{I} T .98$ & $\mathrm{NT}$ \\
\hline
\end{tabular}

Abbreviation: ns: WBC, white blood cells; RBC, red blood cells; Hb, hemoglobin; PLT, platelets; AMY, amylase; T-Bil, total bilirubin; D-Bil, direct bilirubin; LDH, lactate dehydrogenase; CRTN, creatinine; CRP, C-reactive protein; NT, not tested.
Table 2 Laboratory data on admission (= day 5)

\begin{tabular}{ll}
\hline WBC & $162 \times 10^{2} / \mu \mathrm{L}$ \\
RBC & $309 \times 10^{4} / \mu \mathrm{L}$ \\
$\mathrm{Hb}$ & $7.4 \mathrm{~g} / \mathrm{dL}$ \\
$\mathrm{Ht}$ & $22.4 \%$ \\
PLT & $2.4 / \mu \mathrm{L}$ \\
schistocytes & $3+(>5 \%)$ \\
AMY & $96 \mathrm{U} / \mathrm{L}$ \\
P-AMY & $87 \mathrm{U} / \mathrm{L}$ \\
AST & $77 \mathrm{U} / \mathrm{L}$ \\
ALT & $27 \mathrm{U} / \mathrm{L}$ \\
T-Bil & $3 \mathrm{mg} / \mathrm{dL}$ \\
D-Bil & $0.8 \mathrm{mg} / \mathrm{dL}$ \\
LDH & $2121 \mathrm{U} / \mathrm{L}$ \\
BUN & $43 \mathrm{mg} / \mathrm{dL}$ \\
CRTN & $2.51 \mathrm{mg} / \mathrm{dL}$ \\
eGFR & $17 \mathrm{ml} / \mathrm{min} / 1.73 \mathrm{~m}^{2}$ \\
CRP & $14.5 \mathrm{mg} / \mathrm{dL}$ \\
SAA & $690 \mu \mathrm{g} / \mathrm{dL}$ \\
HP & $<10 \mathrm{mg} / \mathrm{dL}$ \\
PT & $119 \%$ \\
PT-INR & 0.91 \\
APTT & $26.1 \mathrm{sec}$ \\
FBG & $316 \mathrm{mg} / \mathrm{dL}$ \\
AT III & $76 \%$ \\
D-Ddimer & $8.5 \mu \mathrm{g} / \mathrm{dL}$ \\
Direct Coombs & $(-)$ \\
\hline Abbrevtion
\end{tabular}

Abbreviations: WBC, white blood cells; RBC, red blood cells; $\mathrm{Hb}$, hemoglobin; PLT, platelets; AMY, amylase; T-Bil, total bilirubin; D-Bil, direct bilirubin; LDH, lactate dehydrogenase; CRTN, creatinine; CRP, C-reactive protein; BUN, blood urea nitrogen; AST, aspartate aminotransferase; ALT, alanine aminotransferase; eGFR, epidermal growth factor receptor; SAA, serum amyloid; Hp, haptoglobin; PT, prothrombin time; PT-INR, prothrombin international normalized ratio; APTT, activated partial thromboplastin time; FBG, fibrinogen; AT III, antithrombin III.

was $17 \mathrm{~mL} /$ minute $/ 1.73 \mathrm{~m}^{2}$. Although D-dimer was high at $8.5 \mu \mathrm{g} / \mathrm{dL}$, prothrombin time and activated partial thromboplastin time and fibrinogen were normal. The results did not suggest disseminated intravascular coagulation. There were schistocytes in her peripheral blood smear $(3+;>5 \%)$. Both direct and indirect Coombs tests were negative. The patient's body temperature was $37.4^{\circ} \mathrm{C}$. She had no neurological abnormalities. With additional tests on day 6, ADAMTS13 activity was $60 \%$ and ADAMTS13 inhibitor was not detected. These tests were determined by a chromogenic ADAMTS13-act-ELISA (ADAMTS13 ELISA Kit: Kainos Inc, Tokyo, Japan). ${ }^{8}$

The patient was initially treated with prednisolone (30 mg/day). She was transfused with red cell concentrate $4 \mathrm{U}$ on day 6 . Her symptoms and progress after developing acute pancreatitis were relatively similar to those from some reports of TTP induced by acute pancreatitis. On day 7, she was diagnosed with acquired secondary TTP. 
The patient started treatment with PE, receiving a total of five treatments. She received PE for 4 consecutive days (from day 7 to day 10) and on day 13 (Figure 1). The dose of fresh frozen plasma (FFP) for PE was $3600 \mathrm{~mL}$ /day for the first 4 days and $2700 \mathrm{~mL} /$ day for the last day. On day $7, \mathrm{Hb}$ was $8.8 \mathrm{~g} / \mathrm{dL}$ and platelet counts were $0.8 \times 10^{4} / \mu \mathrm{L}$ before PE. On day $14, \mathrm{Hb}$ and platelet counts were $7.7 \mathrm{~g} / \mathrm{dL}$ and $46.4 \times 10^{4} / \mu \mathrm{L}$, respectively. ADAMTS13 activity was $75 \%$ on day 17 and $78 \%$ on day 31 . The dose of prednisolone was tapered. She did not require any additional treatments. She was discharged from our hospital on day 39. She has maintained remission for 1 year and has not suffered a relapse.

\section{Discussion}

TTP is clinically characterized by five typical symptoms: hemolytic anemia, thrombocytopenia, renal impairment, fever, and neurological disorders. ${ }^{1}$ However, none of these symptoms is a diagnostic characteristic for TTP. Furthermore, it is rare to see all of them together before the disease significantly develops. It is difficult to diagnose TTP from clinical features. In contrast, measurement of ADAMTS13 activity and its inhibitor are useful for the diagnosis of TTP. At the same time, in cases where ADAMTS13 activity is normal or moderately reduced with no presence of the inhibitor, we need to examine the patient history carefully.

Although there are some case reports of TTP associated with acute pancreatitis, this appears to be rare. ${ }^{3-5}$ Among 919 patients who were registered as having TMA across Japan during the period 1998-2008, which comprised a
TMA database of Nara Medical University reported by Fujimura et al, no cases of TMA associated with acute pancreatitis were recorded. ${ }^{3}$ In the clinical course of our patient, there were schistocytes in her peripheral blood smear and she did not have any effects from PC transfusion. Although we suspected that her symptoms were caused by TTP, it was not easy to make a definite diagnosis of TTP because this was occurring while acute pancreatitis was developing and ADAMTS13 activity deficiency was moderate without its inhibitor. McDonald et al described the following findings, which were based on seven cases of TTP induced by acute pancreatitis: the median time from presentation with pancreatitis to the development of laboratory or clinical features of TTP was 3 days; with the onset of TTP, all patients had a fall in $\mathrm{Hb}$ and platelets; and at the time of onset of TTP, the disease markers for pancreatitis were improving. ${ }^{4}$ Similar findings were also observed in our patient. In addition, McDonald et al noted that ADAMTS13 activity was only moderately reduced with no presence of the inhibitor. ${ }^{4}$ Similar findings have been reported in other studies. ${ }^{5,9}$ We speculate that ADAMTS13 activity was moderately reduced at the onset of TTP because it was slightly lower than that on day 31 .

The relationship between acute pancreatitis and TTP is unclear. However, it is recognized that ADAMTS13 activity is reduced by acute inflammatory disease. ${ }^{10}$ Inflammation with acute pancreatitis results in not only damage to the pancreas but it also impairs the microcirculation in multiple organs. ${ }^{11}$ An increase in inflammatory cytokines in the

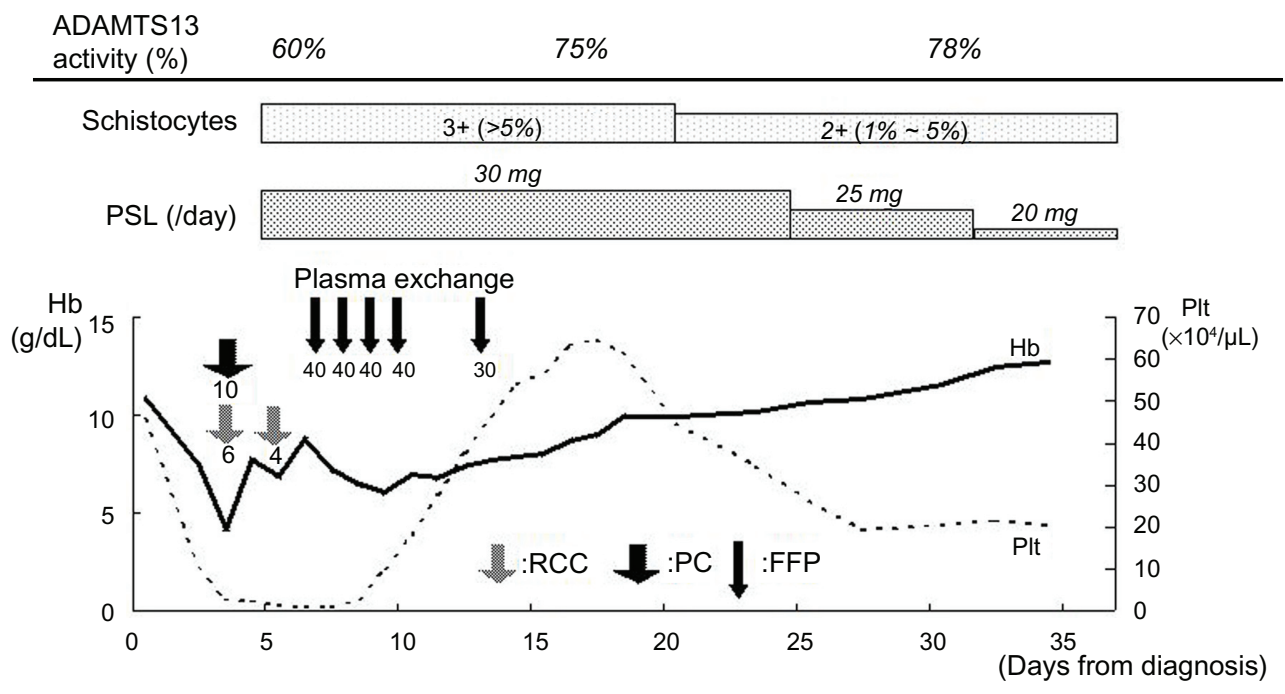

Figure I Clincial course of the patient.

Abbreviations: Hb, hemoglobin; PSL, prednisolone; Plt, platelets; RCC, red cell concentrate; PC, platelet cells; FFP, fresh frozen plasma. 
peripheral blood of patients with acute pancreatitis is now considered as one of the causes of TTP. ${ }^{12}$ Morioka et al reported that concentrations of interleukin 6 (IL-6), IL-8 and tumor necrosis factor- $\alpha$ were increased in patients with acute pancreatitis. ${ }^{11,13}$ These cytokines can be a prognostic factor with severe acute pancreatitis. In fact, it has been demonstrated in vitro that IL-6 interrupts or inhibits cleavage of ULVWF by ADAMTS13, and IL- 8 and TNF- $\alpha$ precipitate a release of ULVWF by activating endothelial cells. ${ }^{14}$ This could lead to decreased ADAMTS13 activity due to IL-6 and increased ULVWF due to IL- 8 and TNF- $\alpha$, which suggests an association of microthrombosis with excessive platelet activation. It is believed that an imbalance between enzyme and substrate caused by inflammatory cytokines could trigger TTP. ${ }^{15,16}$

The guidelines of the British Committee for Standards in Haematology recommend that PE is continued for a minimum of 2 days after the platelet counts return to normal $\left(>150,000 / \mathrm{mm}^{3}\right)$ for TTP. ${ }^{17,18}$ In our case, after the patient was diagnosed with TTP, she began treatment with PE immediately. Her platelet counts recovered well after having four treatments with PE. This rapid recovery is the reason why we only gave one additional PE and the dose of FFP was decreased after her platelet counts returned within the normal range. Platelet counts showed an improvement between days 7 and 14 but Hb levels did not improve. However, $\mathrm{Hb}$ showed a slower response to PE than platelet counts. ${ }^{1}$ In fact, the patient's $\mathrm{Hb}$ gradually recovered after recovering from thrombocytopenia (Figure 1). The effect of PE in TTP is well known. Inflammatory cytokines could be a factor in precipitating TTP as mentioned above. This suggests that PE also plays an important role in the removal of these cytokines in addition to supplementing ADAMTS13 and removing ULVWF. This could ensure that patients return to a normal balance between ADAMTS13 and ULVWF more effectively.

We can assume that our patient progressed well with appropriate treatments. She has not had any relapses. PE provided a clinical benefit for our patient who developed acquired secondary TTP induced by acute pancreatitis. The etiologies of TTP are diverse. The association between TTP and acute pancreatitis are still unknown and this has rarely been reported. However, it is becoming apparent that pancreatitis can trigger TTP by a pathogenic mechanism associated with inflammatory cytokines. In cases where a patient who is developing pancreatitis has a sharp fall in $\mathrm{Hb}$ or platelet counts, the possibility of TTP should be considered, especially with the finding of schistocytes in a blood smear.
A prompt diagnosis of TTP is important to be able to begin immediate treatment.

\section{Disclosure}

The authors declare no conflicts of interest in this work.

\section{References}

1. George JN. How I treat patients with thrombotic thrombocytopenic purpura: 2010. Blood. 2010;116(20):4060-4069.

2. Scully MA, Machin SJ. The pathogenesis and management of thrombotic microangiopathies. Int J Lab Hematol. 2009;31(3):268-276.

3. Fujimura Y, Matsumoto M. Registry of 919 Patients with Thrombotic Microangiopathies across Japan: database of Nara Medical University during 1998-2008. Intern Med. 2010;49(1):7-15.

4. McDonald V, Laffan M, Benjamin S, et al. Thrombotic thrombocytopenic purpura precipitated by acute pancreatitis: a report of seven cases from a regional UK TTP registry. $\mathrm{Br} J$ Hematol. 2009;144(3):430-433.

5. Swisher KK, Doan JT, Vesely SK, et al. Pancreatitis preceding acute episodes of thrombotic thrombocytopenic purpura-hemolytic uremic syndrome: report of five patients with a systematic review of published report. Haematologica. 2007;92(7):936-943.

6. Rock GA, Shumak KH, Buskard NA, et al. Comparison of plasma exchange with plasma infusion in the treatment of thrombotic thrombocytopenic purpura. N Engl J Med. 1991;325(6):393-397.

7. Mori Y, Wada H, Gabazza EC, et al. Predicting response to plasma exchange in patients with thrombotic thrombocytopenic purpura with measurement of vWF-cleaving protease activity. Transfusion. 2002;42(5):572-580.

8. Kato S, Matsumoto M, Matsuyama T, et al. Novel monoclonal antibody-based enzyme immunoassay for determining plasma levels of ADAMTS13 activity. Transfusion. 2006;46(8):1444-1452.

9. Ruiz J, Koduri PR, Valdivieso M, et al. Refractory post-pancreatitis thrombotic thrombocytopenic purpura: response to rituximab. Ann Haematol. 2005;84(4):267-268.

10. Mannucci PM, Canciani MT, Forza I, et al. Changes in health and disease of the metalloprotease that cleaves von Willebrand factor. Blood. 2001;98(9):2730-2735.

11. Morioka C, Uemura M, Matsuyama T, et al. Plasma ADAMTS13 activity parallels the APACHE II score, reflecting an early prognostic indicator for patients with severe acute pancreatitis. Scand J Gastroenterol. 2008;43(11):1387-1396.

12. Al Mofleh IA. Severe acute pancreatitis: pathogenetic aspects and prognostic factors. World J Gastroenterol. 2008;14(5):675-684.

13. Mayer J, Rau B, Gansauge F, Beger HG. Inflammatory mediators in human acute pancreatitis: clinical and pathophysiological implications. Gut. 2000;47(4):546-552.

14. Bernardo A, Ball C, Nolasco L, Moake JF, Dong JF. Effects of inflammatory cytokines on the release and cleavage of the endothelial cellderived ultralarge von Willebrand factor multimers under flow. Blood. 2004;104(1):100-106.

15. Claus RA, Bockmeyer CL, Sossdorf M, Losche W. The balance between von-Willebrand factor and its cleaving protease ADAMTS13: biomarker in systemic inflammation and development of organ failure? Curr Mol Med. 2010;10(2):236-248.

16. Bockmeyer CL, Claus RA, Budde U, et al. Inflammation-associated ADAMTS13 deficiency promotes formation of ultra-large von Willebrand factor. Haematologica. 2008;93(1):137-140.

17. George JN. Clinical practice. N Engl J Med. 2006;354(18): 1927-1935.

18. Allford SL, Hunt BJ, Rose P, et al. Guidelines on the diagnosis and management of the thrombotic microangiopathic haemolytic anaemias. Br J Haematol. 2003;120(4):556-573. 
International Journal of General Medicine

Dovepress

\section{Publish your work in this journal}

The International Journal of General Medicine is an international, peer-reviewed open-access journal that focuses on general and internal medicine, pathogenesis, epidemiology, diagnosis, monitoring and treatment protocols. The journal is characterized by the rapid reporting of reviews, original research and clinical studies across all disease areas.
A key focus is the elucidation of disease processes and management protocols resulting in improved outcomes for the patient. The manuscript management system is completely online and includes a very quick and fair peer-review system. Visit http://www.dovepress.com/ testimonials.php to read real quotes from published authors.

Submit your manuscript here: http://www.dovepress.com/international-journal-of-general-medicine-journal 